Discussion Paper No. 06-043

\title{
Evaluating Conditional Asset Pricing Models for the German Stock Market
}

Andreas Schrimpf, Michael Schröder and Richard Stehle

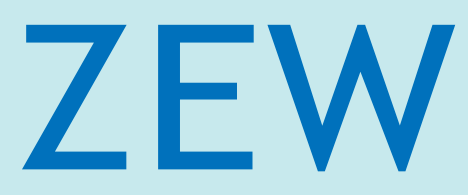

Zentrum für Europäische Wirtschaftsforschung $\mathrm{GmbH}$ Centre for European Economic Research 
Discussion Paper No. 06-043

\title{
Evaluating Conditional Asset Pricing Models for the German Stock Market
}

\author{
Andreas Schrimpf, Michael Schröder \\ and Richard Stehle
}

Download this ZEW Discussion Paper from our ftp server:

ftp://ftp.zew.de/pub/zew-docs/dp/dp06043.pdf

Die Discussion Papers dienen einer möglichst schnellen Verbreitung von neueren Forschungsarbeiten des ZEW. Die Beiträge liegen in alleiniger Verantwortung der Autoren und stellen nicht notwendigerweise die Meinung des ZEW dar.

Discussion Papers are intended to make results of ZEW research promptly available to other economists in order to encourage discussion and suggestions for revisions. The authors are solely responsible for the contents which do not necessarily represent the opinion of the ZEW. 


\section{Non-technical Summary}

The inability of the capital asset pricing model (CAPM) to explain the crosssectional variation of average stock returns is well documented in the empirical asset pricing literature. Given the dismal performance of the static CAPM, numerous studies have investigated potential reasons for the empirical weakness. A prominent explanation for the empirical failure of the static CAPM is that the implications of conditioning information have been neglected. Most studies on conditional versions of the CAPM, allowing either for time-variation of the betas or the parameters of the stochastic discount factor, have found that by incorporating conditioning information, the empirical performance is clearly improved.

The main motivation of this paper is to study the performance of the model class of the conditional CAPM in explaining the variation of average stock returns of the German stock market. Since previous empirical evidence is mainly based on studies for the U.S. stock market, we provide an additional robustness check for conditional asset pricing models. The unconditional CAPM and the Fama-French three-factor model serve as benchmarks in our analysis. 16 portfolios sorted by size and book-to-market are used as test assets.

Our empirical results can be summarized as follows. We present further evidence regarding the empirical shortcomings of the unconditional CAPM in explaining German stock returns. Most importantly, our results suggest that incorporating conditioning information has the potential to substantially improve the model's performance. The choice of the conditioning variable, however, is crucial for the results. According to our empirical findings, a specification of the conditional CAPM with the term spread as the conditioning variable is able to explain the cross-section of returns about as well as the Fama-French model. Also the performance of the conditional CAPM using a January-dummy variable is encouraging, given the fact that it is only a slight modification of the standard model. There is no evidence that the use of conditioning variables necessarily leads to increased parameter instability. By contrast, the null hypothesis of stable parameters is rejected in the case of the three-factor model of Fama and French. Additional test results reveal however, that unconditional model specifications perform quite well in capturing the time-series predictability of the test asset returns. 


\title{
Evaluating Conditional Asset Pricing Models for the German Stock Market*
}

\author{
Andreas Schrimpf, ZEW Mannheim ${ }^{\dagger}$ \\ Michael Schröder, ZEW Mannheim \\ Richard Stehle, Humboldt Universität Berlin
}

July 3, 2006

\begin{abstract}
We study the performance of conditional asset pricing models in explaining the German cross-section of stock returns. Our test assets are portfolios sorted by size and book-to-market as in the paper by Fama and French (1993). Our results show that the empirical performance of the Capital Asset Pricing Model (CAPM) can be improved substantially when allowing for time-varying parameters of the stochastic discount factor. A conditional CAPM with the term spread as a conditioning variable is able to explain the cross-section of German stock returns about as well as the Fama-French model. Structural break tests do not indicate parameter instability of the model - whereas the reverse is found for the Fama-French model. Unconditional model specifications however do a better job than conditional ones at capturing time-series predictability of the test portfolio returns.
\end{abstract}

JEL Classification: G12

Keywords: Asset Pricing, Conditioning Information, Hansen-Jagannathan Distance, Multifactor Models

\footnotetext{
${ }^{*}$ Access to the German interest rate and bond database of Wolfgang Bühler, University of Mannheim, is gratefully acknowledged. We thank Erik Lüders, Waldemar Rotfuss (ZEW) and seminar participants at HU Berlin, the joint graduate student finance seminar of the Universities of Cologne and Tübingen and the 2006 annual meeting of the EFMA (Madrid) for helpful comments and discussions. We also thank Anja Schulz for substantial assistance with data construction and Stefan Frey and Joachim Grammig for providing us with their GMM library for GAUSS. Zohal Hessami provided excellent research assistance. This research benefitted from financial support of Fritz Thyssen Stiftung. All remaining errors and omissions are the responsibility of the authors.

${ }^{\dagger}$ Corresponding author: Andreas Schrimpf, Centre for European Economic Research (ZEW), Mannheim, P.O. Box 1034 43, 68034 Mannheim, Germany, email: schrimpf@zew.de, phone: +49621 1235160, fax: +49621 1235223 .
} 


\section{Introduction}

It is widely known that the Capital Asset Pricing Model (CAPM) has severe problems in explaining empirical patterns of the cross-section of U.S. stock returns in the post-1963 period [e.g. Banz (1981), Basu (1983), Rosenberg, Reid and Lanstein (1985)]. ${ }^{1}$ The most serious blow to the CAPM has been the work by Fama and French (1992) who demonstrated the inability of the CAPM's beta to explain the cross-section of stock returns. Instead, two variables (size and the bookto-market ratio) are found to bear a strong relation to the cross-sectional variation of average stock returns. In the light of this empirical evidence, numerous attempts have been made to extend the CAPM in order to achieve empirical success.

Several authors have argued that the empirical failure of the CAPM can be attributed to the fact that the conditional implications of the model have been neglected previously. ${ }^{2}$ These papers are based on the literature on time series predictability of excess stock returns at long-horizons, which suggests that risk premia are time-varying [e.g. Campbell and Shiller (1988), Fama and French (1989) and Lettau and Ludvigson (2001a)]. ${ }^{3}$ The implication for the econometric testing of asset pricing models is that the parameters of the stochastic discount factor (SDF) are potentially time-varying.

As yet, the research on conditional asset pricing models has focused primarily on the U.S. stock market. However, an important out-of sample check for an asset pricing model is the question whether the results for the U.S. also hold for other developed capital markets. The purpose of this paper is therefore to evaluate several specifications of the conditional CAPM for a major European market, the

\footnotetext{
${ }^{1}$ Ang and Chen (2005) argue that the CAPM works much better during the longer period from 1927 to 2001. They attribute their findings to two effects: on the one hand betas of bookto-market portfolios vary substantially over time and additionally the post-1963 period is rather short for the conventional test procedures.

${ }^{2}$ Prominent contributions include for instance Harvey (1989), Ferson and Harvey (1991), Jagannathan and Wang (1996), Lettau and Ludvigson (2001b), Hodrick and Zhang (2001). For a critical view of conditional asset pricing models see Lewellen and Nagel (2005). Ang and Chen (2005), however, show that the rolling time-series OLS methodology applied by Lewellen and Nagel leads to biased estimates of the parameters of the conditional CAPM.

${ }^{3}$ Cochrane (2001, ch.20) provides an excellent survey on the predictability of stock returns. For critical views regarding the time-series predictability of returns, see for instance Goyal and Welch (2004) and Ang and Bekaert (2005).
} 
German stock market. In this way, our study provides an additional robustness check for conditional asset pricing models. As our test assets, we use 16 portfolios of German stocks sorted by size and book-to-market which are constructed in the same way as in the seminal paper by Fama and French (1993). For the empirical tests we use the excess returns of these portfolios over the German short-term interest rate. We also include the short-term interest rate as an additional test asset, in order to identify the mean of the stochastic discount factor, i.e. we have 17 moment conditions in total. Our estimations are based on monthly data for the time period ranging from 1969:12 to 2002:12.

There are certain criteria for the choice of conditioning variables. It has been suggested in the literature that these variables should capture investors' expectations about future market returns or business cycle conditions. Our set of conditioning variables largely follows the previous literature, in particular Ferson and Harvey (1999). We use the spread between the return on corporate bonds and government bonds $(D E F)$, the term spread $(T E R M)$, short term interest rates $(T B)$ as well as dividend yields $(D I V)$. In order to see whether a "January-effect" plays a role on the German stock market, we follow Hodrick and Zhang (2001) in considering a January-Dummy $J A N$ as a conditioning variable, which allows for different parameters of the SDF in January and other months. ${ }^{4}$ Following Hodrick and Zhang (2001) we also use a variable intended to capture the cyclical component of industrial production $(C Y)$.

It is fair to say that up to now the most prominent model to explain cross-sectional variation in stock returns has been the model by Fama and French (1993). Motivated by the empirical evidence against the CAPM, Fama and French proposed a factor model including two additional risk factors designed to capture risks regarding size $(S M B)$ and book-to-market $(H M L)$. In contrast to the theory-derived conditional CAPM, the Fama-French model is mainly motivated from an empirical perspective, which has been the source of a lot of controversy. There has been an

\footnotetext{
${ }^{4}$ As evinced by Daniel and Titman (1997) for the U.S. stock market, the empirical phenomenon that small stocks earn a higher return on average than big stocks ("size premium") and that high book-to-market stocks earn a higher return than growth stocks ("value premium") occurs to a large extent in January months.
} 
ongoing debate on what the true macroeconomic risks behind the Fama-French factors actually are. Fama and French $(1993,1995,1996)$ interpret their model as a version of Ross's (1976) APT or Merton's (1973) ICAPM. Thus, they provide a risk-based interpretation of the $S M B$ and $H M L$ factors. This view has been corroborated recently by the work of Liew and Vassalou (2000) who provided evidence that $S M B$ and $H M L$ contain news regarding future economic growth suggesting that $S M B$ and $H M L$ are indeed proxies for more fundamental macroeconomic risks. Petkova (2006) finds evidence that $S M B$ and $H M L$ are correlated with innovations in predictive variables such as the default spread and the term spread. Nevertheless, the model remains controversial. However, owing to its empirical success in explaining the cross-section of portfolio returns, it constitutes a natural benchmark model for our model comparison tests.

Since the purpose of our paper is to run a horse race among different linear factor models, we estimate various model specifications by the Generalized Method of Moments (GMM) using the second moment matrix of returns as the weighting matrix, as proposed by Hansen and Jagannathan (1997). The authors have shown that by doing so, the solution to the GMM problem amounts to minimizing the distance between the set of true stochastic discount factors and the proxy for the SDF implied by the respective asset pricing model. Following Jagannathan and Wang (1996) and Hodrick and Zhang (2001), we test whether this distance is zero. There is another reason for choosing the second moment matrix of returns as our weighting matrix. The conventional GMM introduced by Hansen (1982) uses the inverse of covariance matrix of sample moments as a weighting matrix. This weighting matrix usually differs from model to model. Since the purpose of our paper is to analyze different specifications of asset pricing models and to compare their performance to each other on a common data set, it is essential to use the same weighting matrix for all model specifications. Hence, we prefer the Hansen-Jagannathan (HJ) weighting matrix over two-stage GMM in our empirical setup.

We conduct a series of additional robustness checks in order to provide a tough challenge for the different model specifications. Ghysels (1998) has criticized con- 
ditional asset pricing models on the grounds that incorporating conditioning information may lead to greater parameter instability. This can be a serious drawback if the model is to be used out-of-sample in corporate finance applications. Therefore, we augment our model comparison tests with the supLM-Test for parameter stability suggested by Andrews (1993). This test has also been applied by Hodrick and Zhang (2001) and Li, Vassalou and Xing (2001) in empirical frameworks similar to ours. We also investigate the capacity of the different model specifications in capturing the time series predictability of our size and book-to-market portfolio returns according to the test by Farnsworth, Ferson, Jackson and Todd (2002). Moreover, we test whether the factors of the conditional asset pricing models are driven out once the Fama-French factors $S M B$ and $H M L$ are included in the SDF.

Prior research on the German stock market has primarily used time-series and cross-sectional regression methods in order to evaluate empirical asset pricing models. ${ }^{5}$ Earlier studies have investigated for instance the explanatory power of market capitalization, book-to-market ratio and other financial ratios. ${ }^{6}$ In contrast to Fama and French (1993), the additional variables are included as characteristics rather than risk factors. Beiker (1993) finds that the negative relationship between returns and market capitalization which has been found for the U.S. stock market also exists for German stocks but that the phenomenon depends on the sample period. The study of Stehle (1997) confirms the results found by Beiker using all stocks listed at the Frankfurt Stock Exchange during the period from 1954 until 1990. Stocks with a low market capitalization exhibited a significantly higher average return compared to blue chip stocks but most of this extra-return was realized in January and February. Sattler (1994) and Gehrke (1994) find a significantly positive relationship between average stock returns and the book-to-market ratio. In a more recent study Wallmeier (2000) also considers other financial ratios such

\footnotetext{
${ }^{5}$ Two exceptions are the studies by Hafner and Herwartz (1999) and Scheicher (2000) who analyze asset pricing models for individual German stocks in a multivariate GARCH framework.

${ }^{6}$ These studies made use of cross-sectional regressions (in most cases the two-step approach of Fama and MacBeth (1973). See e.g. Beiker (1993); Gehrke (1994); Sattler (1994); Stehle (1997); Bunke, Sommerfeld and Stehle (1999); Wallmeier (2000); Stock (2002) and Schulz and Stehle (2002).
} 
as leverage, price-earnings and price-cash-flow ratio. He finds that book-to-market ratio and price-cash-flow ratio have a highly significant impact on German stock returns whereas size is only of minor importance. Ziegler, Schröder, Schulz and Stehle (2005) estimate different multi-factor models including the CAPM and the Fama-French model using portfolios sorted by size and book-to-market as test assets. The main result from their time-series regressions is that the Fama-French multifactor model clearly outperforms the conventional CAPM in terms of explanatory power and pricing errors.

The empirical results of this paper can be briefly summarized as follows. In line with previous research, we present further evidence regarding the empirical shortcomings of the conventional CAPM in explaining German stock returns. Most importantly, we find that conditioning information leads to substantial improvements of the model's performance. According to our empirical results, the CAPM with $T E R M$ as the conditioning variable is able to explain the cross-section of returns about as well as the Fama-French model. Contrary to Ghysels (1998) for the U.S., we do not find that the use of conditioning variables necessarily leads to increased parameter instability. By contrast, the null hypothesis of stable parameters is rejected in the case of the three-factor model of Fama and French. Additional test results reveal however, that unconditional model specifications perform quite well in capturing the time-series predictability of the test asset returns.

The organization of this paper is as follows. The next section shows briefly how conditioning information can be incorporated into asset pricing models. In section 3 we provide an overview of our data set. Section 4 gives an overview of the empirical methods applied in this study with particular focus on HJ-GMM. Section 5 presents the results of model estimation and comparison tests and provides a discussion of our empirical results. Section 6 concludes. 


\section{Conditional Asset Pricing Models}

Conditional asset pricing models can be conveniently expressed in their stochastic discount factor representation. Assuming the absence of arbitrage opportunities, asset pricing theory states that there is a stochastic discount factor (or pricing kernel) $M_{t+1}$, where

$$
E_{t}\left[M_{t+1} R_{t+1}^{i}\right]=1
$$

holds for all assets $i(i=1, \ldots, N)$ in the economy. $R_{t+1}^{i}$ denotes the gross return of asset $i$ and $E_{t}\left(\cdot \mid \Upsilon_{t}\right)$ represents the expectation taken conditional on the investor's information set $\left(\Upsilon_{t}\right)$ as of time $t$. Assuming the existence of a risk-free rate, equation (1) can also be written as $E_{t}\left[M_{t+1} R_{t+1}^{e i}\right]=0$, where $R_{t+1}^{e i}$ is an excess return of asset $i$ over the risk-free rate $R_{t}^{f} \cdot{ }^{7}$ In the most basic asset pricing model - the consumption-based asset pricing model - the pricing kernel $M_{t+1}$ is equal to the investor's marginal rate of substitution. The focus of this paper, however, is on linear factor models which express the pricing kernel as a linear function of factors:

$$
\tilde{M}_{t+1}=b_{0, t}+b_{1, t}^{\prime} f_{t+1}
$$

where $f_{t+1}$ is a $k$-dimensional vector of factors. We denote the SDF of an asset pricing model as $\tilde{M}_{t+1}$, in order to indicate that it is an approximation of the true $\mathrm{SDF} M_{t+1}$. Equation (2) represents a conditional linear factor model since the parameters $b_{0, t}$ and $b_{1, t}$ are time-varying. It can be shown that the parameters of the SDF of linear factor models such as the CAPM can be expressed as functions of expected excess returns [See e.g. Lettau and Ludvigson (2001b) or Cochrane (2001, ch.8)] Empirical evidence from the literature on time series predictability therefore suggests that the parameters of the SDF are potentially time-varying as

\footnotetext{
${ }^{7}$ The estimation results reported in this paper are based on moment conditions for the excess returns $R_{t+1}^{e i}$ for the 16 test portfolios, $E\left[M_{t+1} R_{t+1}^{e i}\right]=0$, plus an additional moment condition for the gross return of our proxy for the risk-free asset, $E\left[M_{t+1} R_{t}^{f}\right]=1$. The purpose of the latter is to identify the mean of the stochastic discount factor.
} 
in $(2)$.

The moment conditions in (1) are not directly testable since they are based on the information set of the investor $\Upsilon_{t}$ which is not directly observable by an econometrician. As a consequence, asset pricing models are usually tested after transforming equation (1) into an unconditional moment condition by the law of iterated expectations, which leads to $E\left[M_{t+1} R_{t+1}^{i}\right]=1$. This is feasible only when the parameters in (2) are assumed to be constant, i.e. $\tilde{M}_{t+1}=b_{0}+b_{1}^{\prime} f_{t+1}$. In this way, however, the conditional implications of the model are neglected.

A way of incorporating conditioning information into the model is by modelling the parameters $b_{0, t} ; b_{1, t}$ in the SDF in equation (2) as linear functions of lagged instruments $z_{t}$ [See e.g. Cochrane (1996), Hodrick and Zhang (2001)]. In the case when $z_{t}$ is a scalar, the SDF of the scaled factor model is given by

$$
\begin{aligned}
\tilde{M}_{t+1} & =\left(b_{0,1}+b_{0,2} z_{t}\right)+\left(b_{1,1}+b_{1,2} z_{t}\right)^{\prime} f_{t+1} \\
& =b_{0,1}+b_{0,2} z_{t}+b_{1,1}^{\prime} f_{t+1}+b_{1,2}^{\prime}\left(f_{t+1} z_{t}\right) .
\end{aligned}
$$

Apart from the fundamental factors $f_{t+1}$, the scaled model also contains the lagged conditioning variable as well as the interaction term between the fundamental factors and the lagged conditioning variable. Hence, the scaled factor model in (3) is effectively an unconditional multifactor-model, where the factors $\tilde{f}_{t+1}$ are given by $\tilde{f}_{t+1}=\left[z_{t}, f_{t+1}, f_{t+1} z_{t}\right]^{\prime}$ and the coefficients are now constant. Plugging (3) into (1) and taking unconditional expectations, the following unconditional moment restrictions can be obtained by the law of iterated expectations:

$$
E\left[\left(b_{0,1}+b_{0,2} z_{t}+b_{1,1}^{\prime} f_{t+1}+b_{1,2}^{\prime} f_{t+1} z_{t}\right) R_{t+1}^{i}\right]=1 .
$$

These moment conditions for the assets $i(i=1, \ldots, N)$ can be exploited for the estimation of the parameters $b=\left[b_{0,1}, b_{0,2}, b_{1,1}^{\prime}, b_{1,2}^{\prime}\right]^{\prime}$ by the Generalized Method of Moments (GMM). When we estimate the scaled factor model by GMM, we obtain estimates of the parameters $b$ of the stochastic discount factor. Testing the 
hypothesis whether parameter $j$ of the SDF is zero, we can assess whether the $j$ th factor significantly influences the pricing kernel.

Frequently, it is also of interest to analyze if a particular factor $j$ carries a significant risk premium, referred to as $\lambda_{j}$. Such values of $\lambda_{j}$ can be obtained by Fama-MacBeth cross-sectional regressions, but can also be delivered in a GMM framework using $\hat{b}$ and the sample variance-covariance matrix of the factors $\tilde{f}_{t+1}{ }^{8}$ For the purpose of completeness, we therefore also provide estimates of $\lambda$ based on our GMM estimates of $\hat{b}$. The reported standard errors for the estimates of $\lambda_{j}$ are calculated by the delta method.

It should be pointed out that only in the case of the unconditional models (static CAPM, and Fama-French model) it is possible to interpret $\lambda_{j}$ as factor risk price. ${ }^{9}$ This is due to the fact that the unconditional scaled multifactor model is obtained from a conditional factor model in the first place. Combining (1) and (2), one can write the model in its conditional expected return beta representation

$$
E_{t}\left(R_{t+1}^{i}\right)=R_{t}^{0}+\lambda_{t}^{\prime} \beta_{i ; t}
$$

where $\beta_{i ; t}=\operatorname{Cov}_{t}\left(f_{t+1}, f_{t+1}^{\prime}\right)^{-1} \operatorname{Cov}_{t}\left(f_{t+1}, R_{t+1}^{i}\right)$ are the conditional betas of asset $i$, the elements of $\lambda_{t}=-R_{t}^{0} \operatorname{Cov}_{t}\left(f_{t+1}, f_{t+1}^{\prime}\right) b_{1, t}$ are also known as the conditional factor risk premia and $R_{t}^{0}=1 / E_{t}\left(\tilde{M}_{t+1}\right)$ is the conditional zero-beta rate.

Unfortunately, it is not possible to obtain the estimates of the conditional factor risk premia $\lambda_{t}$ for the fundamental factors $f_{t+1}$, since the empirically feasible investigation is based on the unconditional version of the scaled factor model in (4). The estimates of $\hat{b}$ and the assumed linear relationship $b_{1, t}=b_{1,1}+b_{1,2} z_{t}$ can be used to obtain an estimate $\hat{b}_{1, t}$. Under the (restrictive) assumption that the conditional variance-covariance matrix of the factors is constant over time, a time series of period $t$ risk prices $\hat{\lambda}_{t}$ for the fundamental factors can be calculated. We

${ }^{8}$ Rearranging (4) gives the unconditional beta representation of the scaled multifactor model:

$$
E\left(R_{t+1}^{i}\right)=E\left(R_{t}^{0}\right)+\lambda^{\prime} \beta, \quad \beta=\operatorname{Cov}\left(\tilde{f}_{t+1}, \tilde{f}_{t+1}^{\prime}\right)^{-1} \operatorname{Cov}\left(\tilde{f}_{t+1}, R_{t+1}^{i}\right),
$$

where $E\left(R_{t}^{0}\right)$ is the expected zero-beta rate, and $\lambda$ is given by $\lambda=-E\left(R_{t}^{0}\right) \operatorname{Cov}\left(\tilde{f}_{t+1}, \tilde{f}_{t+1}^{\prime}\right) b$.

${ }^{9}$ See Lettau and Ludvigson (2001b) for a discussion. 
conduct this exercise following Lettau and Ludvigson (2001b) in order to check whether the fundamental factors earn on average a positive risk premium.

\section{The Data}

This section gives an overview of the data used for the estimation of the different models. All estimations are based on monthly data ranging from 1969:12 - 2002:12. We first provide details on the construction of our test assets for the German stock market, followed by a discussion of the construction of the risk factors as well as on the conditioning variables for the scaled factor models.

\subsection{Portfolio Returns}

Ever since the influential work by Fama and French (1993), it has been common practice in the empirical asset pricing literature to test asset pricing models on the cross-section of portfolios sorted by size (market value of equity) and the ratio of book-equity to market-equity. Following this tradition, we construct size and book-to-market portfolios for the German stock market. Our data basis comprises all stocks traded on the Frankfurt stock exchange between December 1969 and December 2002, for which the necessary data on market capitalization and book value of common equity are available. Companies with a negative book value are not taken into account. Banks and insurance companies are also not considered because they are subject to special accounting standards. Our source for the book-value of common equity is the German Finance Database (Deutsche Finanzdatenbank, DFDB). The monthly stock returns and the data necessary to compute the market value of equity are obtained from a database maintained by Richard Stehle.

We apply a $(4 \times 4)$ sorting scheme, which results in 16 size and book-to-market portfolios for the German stock market. Since fewer companies are listed on the German stock exchange compared to the U.S., using a $(5 \times 5)$ sorting scheme implies that the 25 portfolios constructed in this way for the German market, 
contain far fewer companies than those in the original paper by Fama and French. In order to avoid potential biases, we prefer to use only 16 stock market portfolios instead of the commonly used 25 in similarly designed studies for the U.S. stock market.

For all stocks, we calculate the quartile breakpoints of market capitalization at the end of June of year $t$ as well as the quartile breakpoints of the book-to-market ratio from December of the preceding year $t-1$. Based on these breakpoints, all stocks are allocated into 16 portfolios according to their individual size and book-to-market ratio. Then value-weighted returns are calculated from July in $t$ to June $t+1$, when a realignment of the portfolios takes place taking into account the new information on size and book-to-market.

Table 1: Summary Statistics: 16 Test Assets

\begin{tabular}{lcccc}
\hline \multicolumn{5}{c}{ Excess returns of test assets, 16 stock portfolios } \\
Mean (standard deviation) \\
\hline Size Quartiles & \multicolumn{5}{c}{ Book-to-market Quartiles } \\
& $B 1$ (Low) & $B 2$ & $B 3$ & $B 4$ (High) \\
\hline S1 (Small) & -0.329 & -0.095 & -0.006 & 0.021 \\
& $(4.848)$ & $(3.743)$ & $(4.036)$ & $(5.066)$ \\
S2 & 0.046 & 0.143 & 0.147 & 0.304 \\
& $(4.134)$ & $(4.146)$ & $(4.432)$ & $(4.524)$ \\
S3 & 0.014 & 0.145 & 0.106 & 0.325 \\
& $(3.956)$ & $(4.184)$ & $(4.576)$ & $(5.276)$ \\
S4 (Big) & 0.007 & 0.337 & 0.417 & 0.472 \\
& $(6.209)$ & $(5.594)$ & $(5.084)$ & $(5.291)$ \\
\hline \hline
\end{tabular}

Note: The returns are the average excess returns (monthly, in \%) on 16 size and book-to-market sorted portfolios of the German stock market. The corresponding standard deviations are reported in parentheses. The table is organized as follows: for instance $S 1 B 1$ contains the average (monthly) excess return of the portfolio containing the smallest stocks in terms of market capitalization and the lowest book-to-market ratio. The sample period is 1969:12 - 2002:12.

Table 1 contains descriptive statistics of our test assets. First of all, it is noteworthy that there is a sizeable spread in the average monthly excess returns of the different portfolios which is to be explained by the different asset pricing models. The largest excess return is $0.472 \%$ for the stock portfolio containing big value stocks (portfolio 
$S 4 B 4$ ), whereas the lowest average excess return is a negative $-0.329 \%$ (portfolio $S 1 B 1)$.

As shown by table 1, the "value premium" can also be observed empirically on the German stock market: moving from growth stocks (low book-to-market for a given size category) to value stocks (high book-to-market for a given size category), we can see that average excess returns tend to rise. It is striking however, that no negative relationship between size and average returns can be found for the German stock market. This finding has been recently reported by Ziegler et al. (2005) who analyzed different types of multifactor models for the German stock market for the period 1968:07-1995:06. Contrary to the sample period studied by Ziegler et al. (2005), one can even observe a tendency that average returns rise when size increases in our extended sample period which also covers more recent data. This finding stands in clear contrast to the pattern documented by numerous studies on the U.S. stock market.

\section{$3.2 \quad$ Factors}

For the construction of our proxy for the market portfolio, we use the valueweighted return on all stocks listed on the Frankfurt stock exchange, including the stocks of banks and insurance companies as well as of those companies which have a negative book value at the end of December of the respective year. We compute the market excess return $R^{m}$ by subtracting the return of our risk-free rate proxy. We choose the money market rate for one-month deposits obtained from the time series database of Deutsche Bundesbank as our proxy for the risk-free rate.

The Fama-French factors $S M B$ and $H M L$ are designed to mimick risk factors regarding to size and book-to-market. The starting point for the construction of $S M B$ (Small minus Big) and $H M L$ (High minus Low) are six portfolios derived in a similar way as the 16 size and book-to-market portfolios. At the end of June of each year $t$, all stocks are sorted by their market capitalization. Then the size median is used as a breakpoint in order to split the stocks into small stocks $(\mathrm{S})$ and big stocks (B). In a similar way, all stocks are sorted into three categories 
according to their book-to-market ratio [low (L), medium (M) and high (H)] at the end of December in year $t-1$. From the intersections of the two size and three book-to-market groups, six portfolios are formed, into which all stocks traded on the Frankfurt stock market are allocated. This procedure results in six portfolios (S/L, S/M, S/H, B/L, B/M, B/H) for which monthly value-weighted returns are calculated. Every year in June, a realignment of the portfolios takes place taking new information on market capitalization and book-to-market into account.

The portfolio $S M B$ (Small minus Big) is intended to mimick the risk factor related to size. It is calculated as the average of the returns of the portfolios containing small stocks (S/L, S/M, S/H) minus the average of the returns of the portfolios containing big stocks (B/L, B/M, B/H). As noted by Fama and French (1993), this construction eliminates the influence of book-to-market in $S M B$. The portfolio $H M L$ (High minus Low) is similarly constructed and designed to capture risk related to book-to-market. It is calculated as the average of the returns of the portfolios containing high book-to-market stocks $(\mathrm{S} / \mathrm{H}, \mathrm{B} / \mathrm{H})$ minus the average of the returns of the portfolios containing low book-to-market stocks (S/L, B/L). Obviously this aims at eliminating the effect of size in $H M L$.

\subsection{Conditioning Variables}

In this paper we use six conditioning variables in total. Our first conditioning variable is the default spread $D E F$, which was constructed using the data for all corporate bonds listed at German security exchanges during the period 1967 until 2002. ${ }^{10}$ The German market for corporate bonds was relatively small in the years until the end of the 1980s but has grown rapidly in the past 15 years: the number of listed bonds increased from 14 in 1989 to 43 in 1994 and 171 in 2002. The default spread variable $D E F$ is constructed as the return on a long position in a value-weighted portfolio consisting of all corporate bonds and a short position in German government bonds. Due to the fact that the duration of the corporate bond portfolio changes over time, the duration of the government bond portfolio

\footnotetext{
${ }^{10}$ We thank Wolfgang Bühler, University of Mannheim, for access to the German interest rate and bond database.
} 
has to be adjusted accordingly. Otherwise $D E F$ would not only measure changes in default risk but also changes in duration. Therefore the government bond portfolio is constructed as a weighted average of REXP sub-indexes with different time to maturity. ${ }^{11}$ The weighting scheme changes over time in order to match the duration of the corporate bond portfolio. The $D E F$ conditioning variable, i.e. the return difference of the two bond portfolios, thus measures changes in default risk for the German corporate bond market. The mean of the DEF factor of $0.136 \%$ (see Table 2) shows that on average investors in German corporate bonds have been rewarded by an additional return of about $1.64 \%$ p.a. for bearing default risk.

The term spread TERM is defined as the difference between the return on longterm government bonds over the short-term interest rate. For the short-term interest rate we use the money market rate for one-month deposits mentioned above. The monthly return on long-term government bonds was calculated from the REXperformance index of government bonds with ten years to maturity. Moreover, also aggregate dividend yields $D I V$ have featured prominently in recent tests of conditional asset pricing models. Our time series of aggregate dividend yields is based on the MSCI Index Germany and was made available to us by MSCI. This paper also considers the short-term interest rate $T B$ as a conditioning variable. Following Hodrick and Zhang (2001), we explore the effect of using a January-dummy $J A N$, which takes the value one in January and zero otherwise.

We also use the cyclical component of industrial production $C Y$ as a conditioning variable as proposed in the paper by Hodrick and Zhang (2001). We construct this variable for Germany using the filter by Hodrick and Prescott (1997) (HP-filter). Our time series of (log-)industrial production is available from 1960:01-2002:12. The period from 1960:01-1969:11 is used to initialize the series. The smoothing parameter is set to 6,400. Then we apply the HP-filter recursively in order to extract the cyclical component of the series. The recursive application of the filter ensures that only information which is truly available to the investor as of time $t$ appears in the information set.

\footnotetext{
${ }^{11}$ The REXP index family consists of 10 sub-indexes each representing a different time to maturity, ranging from 1 year (first sub-index) until 10 years (last sub-index).
} 
Table 2: Summary Statistics: Factors and Conditioning Variables

\begin{tabular}{lcccccccccc}
\hline Variable & & \multicolumn{1}{c}{ Cross Correlation } \\
& Mean & Std. & $R^{m}$ & SMB & HML & TERM & $D E F$ & $R^{f}$ & $D I V$ & $C Y$ \\
\hline$R^{m}$ & 0.235 & 5.265 & 1.000 & & & & & & & \\
$S M B$ & -0.189 & 2.918 & -0.657 & 1.000 & & & & & & \\
$H M L$ & 0.271 & 2.598 & -0.069 & 0.071 & 1.000 & & & & & \\
$D E F$ & 0.136 & 1.282 & -0.002 & 0.015 & -0.004 & 1.000 & & & & \\
$T E R M$ & 0.115 & 1.118 & 0.189 & -0.169 & 0.035 & -0.072 & 1.000 & & & \\
$R^{f}$ & 0.489 & 1.118 & -0.095 & 0.043 & -0.005 & 0.015 & -0.122 & 1.000 & & \\
$D I V$ & 0.296 & 0.095 & -0.100 & 0.102 & -0.039 & 0.088 & -0.079 & 0.591 & 1.000 & \\
$C Y$ & -0.184 & 2.119 & 0.054 & 0.001 & 0.092 & 0.068 & -0.054 & -0.334 & -0.237 & 1.000 \\
\hline \hline
\end{tabular}

Note: The table reports means and standard deviations in (\%, per month) of factors and conditioning variables for the period 1969:12 - 2002:12. Furthermore, correlation coefficients are reported. The set of factors includes the excess return on the market portfolio $R^{m}$ as well as the Fama-French factors $S M B$ and $H M L$. The set of conditioning variables is defined as $z_{t}=\left(D E F_{t}, T E R M_{t}, T B_{t}, D I V_{t}, C Y_{t}\right)^{\prime}$, where $D E F_{t}$ is the default spread, TERM represents the term spread, $T B_{t}$ denotes the short term interest rate, $D I V_{t}$ are aggregate dividend yields, $C Y_{t}$ denotes the cyclical component of industrial production.

Table 3 presents test results for the predictive power of our set of conditioning variables $z_{t}=\left(D E F_{t}, T E R M_{t}, T B_{t}, D I V_{t}, C Y_{t}\right)^{\prime}$. For this purpose we run the following regression

$$
R_{i ; t+1}=a+b^{\prime} z_{t}+\epsilon_{t+1} .
$$

The table reports Wald statistics and the corresponding $p$-values for the test that the lagged conditioning variables bear no relation with the portfolio excess returns, i.e. that the coefficients $b$ are jointly zero. For most portfolios, the null hypothesis can be rejected at the $10 \%$ level. Further descriptive statistics for the factors and the conditioning variables are provided in table 2 .

\section{Empirical Methods}

We estimate the different model specifications using a Generalized Method of Moments (GMM) approach. The appendix also contains empirical results for the traditional cross-sectional regression approach by Fama and MacBeth (1973), mainly for the sake of completeness. Our primary focus, however, is on the variation of the GMM estimation approach proposed by Hansen and Jagannathan (1997), which we briefly outline in the following. 
Table 3: Summary Statistics: Conditioning Variables

\begin{tabular}{lccccc}
\hline Size Quartiles & & \multicolumn{4}{c}{ Book-to-market Quartiles } \\
& & $B 1$ (Low) & $B 2$ & $B 3$ & $B 4$ (High) \\
\hline \multirow{2}{*}{$S 1$ (Small) } & $\chi_{(5)}^{2}$ & 22.217 & 5.863 & 7.380 & 13.303 \\
& & $(0.001)$ & $(0.320)$ & $(0.194)$ & $(0.021)$ \\
\multirow{2}{*}{$S 2$} & & & & & \\
& $\chi_{(5)}^{2}$ & 9.499 & 21.345 & 17.072 & 7.558 \\
& & $(0.091)$ & $(0.001)$ & $(0.004)$ & $(0.182)$ \\
$S 3$ & $\chi_{(5)}^{2}$ & 13.721 & 8.394 & 10.528 & 11.489 \\
& & $(0.018)$ & $(0.136)$ & $(0.062)$ & $(0.043)$ \\
& & & & & \\
$S 4$ (Big) & $\chi_{(5)}^{2}$ & 14.356 & 9.233 & 9.862 & 9.530 \\
& & $(0.014)$ & $(0.100)$ & $(0.079)$ & $(0.090)$ \\
\hline \hline
\end{tabular}

Note: The table reports tests for the predictive power of our set of conditioning variables. The sample period is 1969:12 - 2002:12. The set of conditioning variables is defined as $z_{t}=$ $\left(D E F_{t}, T E R M_{t}, T B_{t}, D I V_{t}, C Y_{t}\right)^{\prime}$, where $D E F_{t}$ is the default spread, $T E R M_{t}$ represents the term spread, $T B_{t}$ denotes the short term interest rate, $D I V_{t}$ are aggregate dividend yields, $C Y_{t}$ denotes the cyclical component of industrial production. The entries of the table are based on the predictive regression $R_{i ; t+1}=a+b^{\prime} z_{t}+\epsilon_{t+1}$. The table reports the Wald statistic for testing the null hypothesis that the coefficients on the predictive variables are jointly equal to zero $\left(H_{0}: b=0\right)$. $p$-values are reported in parentheses.

Asset pricing models are characterized by different approximations $\tilde{M}(b)$ of the "true" SDF in equation (1). Hansen and Jagannathan (1997) have proposed a measure to evaluate by how much the pricing kernel proxy of the respective asset pricing model differs from the set of true pricing kernels $M .{ }^{12}$ They show that the minimum value of the distance has the following expression

$$
\delta=\sqrt{E\left[\tilde{M}(b) R_{t}-1\right]^{\prime} E\left(R_{t} R_{t}{ }^{\prime}\right)^{-1} E\left[\tilde{M}(b) R_{t}-1\right]} .
$$

It is straightforward to map the concept of the HJ-distance into the standard GMM framework. GMM estimation is based on minimizing a quadratic form of the pricing errors of the model. The $N \times 1$ vector of pricing errors is equal to $g(b)=E\left[\tilde{M}(b) R_{t}-1\right]$, whereas the sample analogue is given by

$$
g_{T}(b)=\frac{1}{T} \sum_{t=1}^{T} \tilde{M}_{t}(b) R_{t}-1 .
$$

\footnotetext{
${ }^{12} R_{t}$ in this section denotes an $N \times 1$ vector of gross returns of the assets.
} 
Hansen and Jagannathan propose to use the inverse of the second moment matrix of returns $W=E\left(R_{t} R_{t}{ }^{\prime}\right)^{-1}$ as a weighting matrix for GMM estimation. By doing so, it is ensured that the parameters are chosen such that the distance between the pricing kernel proxy and the true pricing kernel is as small as possible. The $k \times 1$ vector of unknown parameters $b$ of the SDF can hence be determined by solving the GMM criterion:

$$
\min \quad \delta_{T}^{2}=\min _{b} g_{T}(b)^{\prime} W_{T} g_{T}(b)
$$

where $W_{T}$ is given by the empirical counterpart to the Hansen-Jagannathan weighting matrix, i.e. $W_{T}=\left(\frac{1}{T} \sum_{t=1}^{T} R_{t} R_{t}^{\prime}\right)^{-1}$. Jagannathan and Wang (1996, Appendix C) have derived a test for the hypothesis that the HJ-distance is equal to zero, as implied by the candidate asset pricing model. They show that the statistic $T \delta_{T}^{2}$ is asymptotically distributed as a weighted sum of $\chi_{(1)}^{2}$-distributed random variables. We run the simulation suggested by Jagannathan and Wang (1996) 10,000 times in order to determine the $p$-value for testing the null hypothesis $\delta=0$.

This estimation approach is different from the conventional two-stage GMM approach by Hansen (1982) who suggests to use the (inverse) of the estimated variance-covariance matrix of moment conditions as weighting matrix. He shows that by doing so, asymptotically efficient estimates are obtained. Despite this theoretical statistical advantage, we prefer HJ-GMM over two-stage GMM for a number of reasons. Firstly, the GMM objective evaluated at the estimated parameters has an intuitively appealing interpretation as the (squared) distance between the pricing kernel proxy and the set of true discount factors. Most importantly however, the HJ-weighting matrix remains constant from one model to the other. Two-stage GMM on the contrary weights the different moment conditions according to statistical considerations and changes from model to model. Since our paper aims at comparing different models on a common data set, the HJ-approach is more suitable in our empirical setup. For completeness, however, we report the $J_{T}$-statistic by Hansen (1982) as an additional statistic of model fit. Another possibility to have a "level" playing field for model comparisons is by the use of 
the identity matrix as the weighting matrix for GMM. In this way all assets are treated symmetrically in the GMM optimization. Since this approach leads to very similar results as the Fama-Macbeth procedure (Cochrane 2001), we only report the results of the Fama-MacBeth regressions in the appendix.

The finite sample properties of the test whether the HJ-distance is equal to zero have recently been investigated by Ahn and Gadarowski (2004) using simulation techniques. They find that tests of the null $H_{0}: \delta=0$ can exhibit size distortions in finite samples in the sense that a true model is rejected too often. According to their Monte-Carlo experiments, Hansen's (1982) test of overidentifying restrictions has a slightly better empirical performance with this respect. Table 1 of Ahn and Gadarowski (2004) reveals that this over-rejection problem is particularly severe when the number of observations is small and/or the number of test assets is large. ${ }^{13}$ Since none of the model specifications investigated in this paper is rejected neither by the test based on the HJ-distance nor Hansen's $J_{T}$-test, we do not consider this issue further in this paper.

An important robustness check for an asset pricing model is whether the model is subject to structural shifts in the parameters. Apart from the tests mentioned above, we therefore also report results from the test for parameter stability derived by Andrews (1993). The null hypothesis states that there is parameter stability, whereas the alternative is that there is a single structural break at an unknown date. We compute the LM-statistic for $\pi_{1}=15 \%$ to $\pi_{2}=85 \%$ of the sample, which corresponds to the interval recommended by Andrews (1993). Critical values of the maximum of the calculated values (supLM-statistic) are tabulated by Andrews (1993, Table 1).

\footnotetext{
${ }^{13}$ With 25 test assets and 330 observations, which comes closest to our empirical setup (16 test assets and 397 observations), the true model is rejected at the $5 \%$ level in $8.8 \%$ of the cases by the test $H_{0}: \delta=0$ and in $6.9 \%$ of the cases by the $J_{T}$-test.
} 


\section{Results and Discussion}

In the following, we discuss the results of our cross-sectional tests of the different asset pricing models. First, we report empirical results for the unconditional models, i.e. the conventional CAPM as well as the Fama-French three-factor model. Then, empirical results are reported for different specifications of conditional factor models. Moreover, the results of additional robustness tests are also presented in this section.

\subsection{Unconditional Factor Models}

We first discuss the empirical results for the conventional CAPM specification. Table 4 contains the GMM estimation results using the Hansen-Jagannathan weighting matrix and table 8 in the appendix provides the results from the Fama-Macbeth two-pass regression approach. Panel $\mathrm{A}$ in table 4 demonstrates that the market excess return does not influence the pricing kernel significantly. It also does not earn a risk price which is significantly different from zero. In line with previous results in the empirical asset pricing literature, we find that the pricing errors of the CAPM are large when the model is confronted by size and book-to-market sorted portfolios. Particularly big pricing errors occur for small growth stocks and big value stocks. The static CAPM has clearly the worst empirical performance in explaining the cross-section of German stock returns, which is illustrated by the plots of realized excess returns against the fitted excess returns in figure 1 and 3. This is corroborated by the (adjusted) $R^{2}$ of $17.4 \%$ in the cross-sectional FamaMacBeth regressions, which is the smallest of all models investigated in this paper. The estimated Hansen-Jagannathan distance amounts to 0.209. The corresponding $p$-value of $28.7 \%$ indicates that the model cannot be rejected statistically. The same conclusion is obtained by Hansen's test of overidentifying restrictions which we calculate on the basis of two-stage GMM. In general, we find that both model diagnostics lead to the same conclusions in our study. It should be also pointed out that none of the model specifications investigated in our study can be rejected by the two tests. This result differs from the one obtained for the U.S. where usually 
even the Fama-French model is rejected by formal tests such as the $J_{T}$-Test or the test $H_{0}: \delta=0$ when the 25 Fama-French portfolios are used as test assets [See e.g. Hodrick and Zhang (2001)].

Figure 1: HJ-GMM: CAPM and Fama-French Model, Fitted versus Actual Mean Excess Returns, in \% per month, 16 Fama-French portfolios.


Note: The pricing error plots were generated using the results from HJ-GMM estimation. Mean realized excess returns (horizontal axis) are plotted against the mean realized excess returns implied by the respective asset pricing model (vertical axis). The first digit refers to the size quartile (1=Small, $4=\mathrm{Big})$ and the second digit refers to the book-to-market quartile $(1=\mathrm{Low}$, $4=$ High). The test asset are 16 excess returns of size and book-to-market portfolios as well as the gross return of the proxy for the risk-free asset. The sample period is 1969:12 - 2002:12. The two graphs show results for the CAPM and the Fama-French-Model.

Estimation results for the Fama-French three-factor model that uses $S M B$ and $H M L$ as additional factors are reported in panel $\mathrm{B}$ of tables 4 and 8. The only factor which is statistically relevant for the pricing kernel is $H M L$. It is also the only factor which earns a significant price of risk as indicated by the $t$-statistic of 2.202 for the estimated factor risk premium $\lambda_{H M L}$. It is striking that $S M B$ earns a negative factor risk premium, which is in contrast to the general findings obtained for the U.S. stock market. When looking at the pricing error plots in figures 1 and 3, it becomes apparent that the Fama-French three-factor model clearly outperforms the CAPM. This is also reflected by the higher adjusted $R^{2}$ of $47.8 \%$ in the Fama-MacBeth cross-sectional regressions. Thus, our estimations confirm the earlier results for the German stock market by Ziegler et al. (2005) who found a superior performance of the Fama-French model over the unconditional CAPM using a time-series OLS approach. The Fama-French model does a clearly better job than the CAPM in capturing the value premium, however does a similarly bad 
Table 4: Estimation results HJ-GMM : CAPM and Fama-French Model.

\begin{tabular}{|c|c|c|c|c|}
\hline \multicolumn{5}{|c|}{ Panel A: Non-scaled CAPM } \\
\hline Parameter of the $S D F$ : & const. & $b_{m}$ & & \\
\hline Estimate & 0.997 & -0.858 & & \\
\hline$t$-statistic & & -0.843 & & \\
\hline Factor risk price: & & $\lambda_{m}$ & & \\
\hline Estimate & & 0.002 & & \\
\hline$t$-statistic & & 0.843 & & \\
\hline Model tests: & $J_{T}$-Stat. & HJ-Dist. & supLM & \\
\hline Statistic & 17.511 & 0.209 & 1.226 & \\
\hline$p$-value & 0.289 & 0.287 & & \\
\hline \multicolumn{5}{|c|}{ Panel B: Fama-French Model } \\
\hline Parameter of the SDF: & const. & $b_{m}$ & $b_{S M B}$ & $b_{H M L}$ \\
\hline Estimate & 1.014 & -0.021 & 2.555 & -5.153 \\
\hline$t$-statistic & & -0.015 & 1.019 & -2.290 \\
\hline Factor risk price: & & $\lambda_{m}$ & $\lambda_{S M B}$ & $\lambda_{H M L}$ \\
\hline Estimate & & 0.002 & -0.002 & 0.003 \\
\hline$t$-statistic & & 0.753 & -1.238 & 2.202 \\
\hline Model tests: & $J_{T}$-Stat. & HJ-Dist. & supLM & \\
\hline Statistic & 10.477 & 0.166 & $29.248^{* * *}$ & \\
\hline$p$-value & 0.655 & 0.667 & & \\
\hline
\end{tabular}

Note: The table reports the results of GMM estimation for the unconditional CAPM and the Fama-French model. The sample period is 1969:12 - 2002:12. We report both estimates of the parameters of the SDF $b_{j}$ and factor risk premia $\lambda_{j}$ calculated from these estimates. The standard errors of the latter were calculated using the delta method. *,** and *** means that Andrew's supLM-statistic is significant at the 10,5 or $1 \%$ level.

job in pricing the small growth portfolio. Nevertheless, we find that the model has a serious drawback: our structural break tests reveal that the model suffers from unstable parameters as indicated by a significant supLM-statistic.

\subsection{Main Empirical Results: Conditional CAPM}

We now turn to the main results for the different versions of the conditional CAPM. The results from HJ-GMM are provided in table 5 and the estimation results from the Fama-MacBeth regressions are given in table 9 in the appendix. Pricing error plots are shown in figures 2 and 4 respectively. We consider six model specifications in total. We incorporate each conditioning variable separately into the SDF in order to avoid overfitting. 
The first specification of the conditional CAPM uses the default spread $D E F$ as scaling variable. According to our empirical findings, this conditioning variable does not help much to improve the performance of the CAPM in explaining crosssectional returns. None of the factors significantly influences the pricing kernel. The HJ-distance only falls slightly in comparison to the unconditional CAPM. This rather weak empirical performance may also be due to the fact that we only have a rather noisy measure for the German Default Spread at our disposal, as discussed in section 3.3. As indicated by the pricing error plots, scaling by $D E F$ only induces a small reduction in pricing errors. The null hypothesis of parameter stability, however, cannot be rejected according to Andrew's supLM-test for this model.

We also checked whether the risk price for the fundamental factor (excess return of the market portfolio) is positive on average, i.e. $E\left(\lambda_{t}^{m}\right) \geq 0$ [See discussion in section 2]. This turned out to be the case for all specifications of the conditional CAPM except the model scaled by the default spread.

We next consider the term spread TERM as a conditioning variable for the conditional CAPM. Panel B of table 5 shows that $b_{\text {TERM }}$ is significant at the $10 \%$ level, thus indicating that it is an important component of the pricing kernel. The market excess return and the interaction term between the market excess return and the lagged term spread are not significant. We find that the CAPM scaled by TERM exhibits the best empirical performance of all scaled and non-scaled models in explaining the cross-sectional variation of German stock returns. It has the smallest HJ-distance (0.139) among all models investigated in this study and the $p$-value for the test $H_{0}: \delta=0$ is equal to $99.1 \%$. This result is also reflected by the small pricing errors (figures 2 and 4), which are smaller than those of the Fama-French three-factor model. As reported in table 9 , the adjusted $R^{2}$ is about $57 \%$, which is the highest of all models estimated in this paper. Note also that the model passes the test for parameter stability by Andrews (1993) in contrast to the Fama-French three-factor model. 
Figure 2: HJ-GMM: conditional CAPM, Fitted versus Actual Mean Excess Returns, in \% per month, 16 Fama-French portfolios.
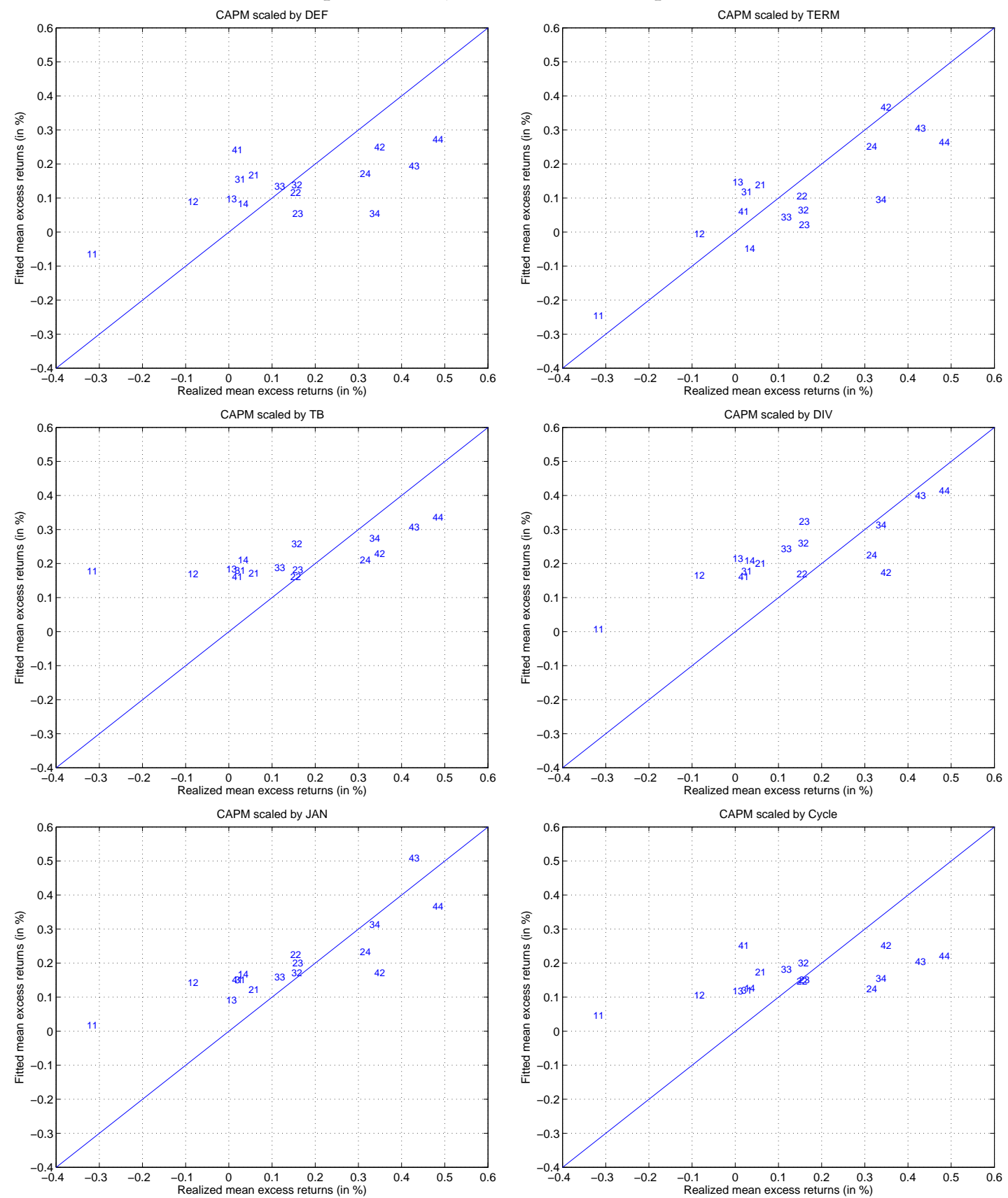

Note: The pricing error plots were generated using the results from HJ-GMM estimation. Mean realized excess returns (horizontal axis) are plotted against the mean realized excess returns implied by the respective asset pricing model (vertical axis). The first digit refers to the size quartile ( $1=$ Small, $4=$ Big) and the second digit refers to the book-to-market quartile ( $1=$ Low, $4=$ High). The sample period is 1969:12 - 2002:12. The upper two graphs show results for the CAPM scaled by the default spread $D E F$ and the term spread $T E R M$. In the middle the pricing error plots of the CAPM scaled by the short-term interest rate $T B$ and by dividend yields $D I V$ are illustrated. At the bottom plots for the CAPM scaled by the January dummy $J A N$ and the cyclical component of industrial production $C Y$ are presented. 
Table 5: Estimation results HJ-GMM: conditional CAPM

\begin{tabular}{|c|c|c|c|c|}
\hline \multicolumn{5}{|c|}{ Panel A: CAPM scaled by DEF } \\
\hline Parameter of the $S D F\left(b_{j}\right)$ : & const. & $b_{m}$ & $b_{D E F}$ & $b_{D E F \cdot m}$ \\
\hline Estimate & 0.998 & -0.107 & -0.353 & -4.680 \\
\hline$t$-statistic & & -0.074 & -1.102 & -1.038 \\
\hline $\operatorname{Lambda}\left(\lambda_{j}\right):$ & & $\lambda_{m}$ & $\lambda_{D E F}$ & $\lambda_{D E F \cdot m}$ \\
\hline Estimate & & 0.003 & 0.333 & 0.014 \\
\hline$t$-statistic & & 0.710 & 1.051 & 0.973 \\
\hline Model tests: & $J_{T}$-Stat. & HJ-Dist. & supLM & \\
\hline Statistic & 13.658 & 0.198 & 10.087 & \\
\hline$p$-value & 0.398 & 0.444 & & \\
\hline \multicolumn{5}{|c|}{ Panel B: CAPM scaled by TERM } \\
\hline Parameter of the $S D F\left(b_{j}\right)$ : & const. & $b_{m}$ & $b_{T E R M}$ & $b_{T E R M \cdot m}$ \\
\hline Estimate & 0.966 & -2.776 & 0.708 & 8.170 \\
\hline$t$-statistic & & -1.494 & 1.665 & 1.286 \\
\hline $\operatorname{Lambda}\left(\lambda_{j}\right):$ & & $\lambda_{m}$ & $\lambda_{T E R M}$ & $\lambda_{T E R M \cdot m}$ \\
\hline Estimate & & 0.002 & -0.763 & -0.026 \\
\hline$t$-statistic & & 0.461 & -1.781 & -1.547 \\
\hline Model tests: & $J_{T}$-Stat. & HJ-Dist. & supLM & \\
\hline Statistic & 4.498 & 0.139 & 6.411 & \\
\hline$p$-value & 0.985 & 0.991 & & \\
\hline \multicolumn{5}{|c|}{ Panel C: CAPM scaled by TB } \\
\hline Parameter of the $S D F\left(b_{j}\right)$ : & const. & $b_{m}$ & $b_{T B}$ & $b_{T B \cdot m}$ \\
\hline Estimate & 0.985 & -1.668 & -0.143 & -3.204 \\
\hline$t$-statistic & & -1.264 & -0.417 & -1.172 \\
\hline $\operatorname{Lambda}\left(\lambda_{j}\right):$ & & $\lambda_{m}$ & $\lambda_{T B}$ & $\lambda_{T B \cdot m}$ \\
\hline Estimate & & 0.002 & 0.123 & 0.007 \\
\hline$t$-statistic & & 0.659 & 0.358 & 0.914 \\
\hline Model tests: & $J_{T}$-Stat. & HJ-Dist. & supLM & \\
\hline Statistic & 15.898 & 0.200 & $45.266^{* * *}$ & \\
\hline$p$-value & 0.255 & 0.317 & & \\
\hline
\end{tabular}

Note: The table reports the results of GMM estimation for the different specifications of the conditional CAPM. DEF is the default spread, TERM is the term spread, DIV denotes dividend yields and $T B$ is the short-term interest rate. $J A N$ is a January-Dummy which takes 1 in January and zero otherwise. $C Y$ is the cyclical component of log-industrial production. The sample period is 1969:12 - 2002:12. We report both estimates of the parameters of the SDF $\left(b_{j}\right)$ and Lambdas $\left(\lambda_{j}\right)$ calculated from these estimates. The standard errors of the $\lambda_{j} s$ are calculated using the delta method. ${ }^{*}, * *$ and ${ }^{* * *}$ means that the supLM-statistic is significant at the 10,5 or $1 \%$ level. 
Table 5: cont.

\begin{tabular}{|c|c|c|c|c|}
\hline \multicolumn{5}{|c|}{ Panel D: CAPM scaled by DIV } \\
\hline $\begin{array}{l}\text { Parameter of the SDF }\left(b_{j}\right) \text { : } \\
\text { Estimate } \\
\text {-statistic } \\
\text { Lambda }\left(\lambda_{j}\right) \text { : } \\
\text { Estimate } \\
\text { t-statistic } \\
\text { Model tests: } \\
\text { Statistic } \\
p \text {-value }\end{array}$ & $\begin{array}{l}J_{T} \text {-Stat. } \\
12.210 \\
0.511\end{array}$ & $\begin{array}{l}b_{m} \\
-3.073 \\
-2.073 \\
\lambda_{m} \\
0.001 \\
0.176 \\
\text { HJ-Dist. } \\
0.178 \\
0.548\end{array}$ & $\begin{array}{l}b_{D I V} \\
0.348 \\
1.088 \\
\lambda_{D I V} \\
-0.339 \\
-1.058 \\
\text { supLM } \\
79.933^{* * *}\end{array}$ & $\begin{array}{l}b_{D I V \cdot m} \\
-6.433 \\
-2.176 \\
\lambda_{D I V \cdot m} \\
0.013 \\
2.013\end{array}$ \\
\hline \multicolumn{5}{|c|}{ Panel E: CAPM scaled by JAN } \\
\hline $\begin{array}{l}\text { Parameter of the } S D F\left(b_{j}\right) \text { : } \\
\text { Estimate } \\
t \text {-statistic } \\
\text { Lambda }\left(\lambda_{j}\right) \text { : } \\
\text { Estimate } \\
t \text {-statistic } \\
\text { Model tests: } \\
\text { Statistic } \\
p \text {-value }\end{array}$ & $\begin{array}{l}J_{T} \text {-Stat. } \\
6.623 \\
0.921\end{array}$ & $\begin{array}{l}b_{m} \\
2.298 \\
1.355 \\
\lambda_{m} \\
0.003 \\
0.709 \\
\text { HJ-Dist. } \\
0.160 \\
0.897\end{array}$ & $\begin{array}{l}b_{J A N} \\
0.072 \\
0.085 \\
\lambda_{J A N} \\
0.044 \\
0.770 \\
\text { supLM } \\
16.274^{*}\end{array}$ & $\begin{array}{l}b_{J A N \cdot m} \\
-52.003 \\
-1.807 \\
\lambda_{J A N \cdot m} \\
0.009 \\
1.911\end{array}$ \\
\hline \multicolumn{5}{|c|}{ Panel F: CAPM scaled by CY } \\
\hline $\begin{array}{l}\text { Parameter of the } S D F\left(b_{j}\right) \text { : } \\
\text { Estimate } \\
t \text {-statistic } \\
\text { Lambda }\left(\lambda_{j}\right) \text { : } \\
\text { Estimate } \\
t \text {-statistic } \\
\text { Model tests: } \\
\text { Statistic } \\
p \text {-value }\end{array}$ & $\begin{array}{l}J_{T} \text {-Stat. } \\
16.794 \\
0.209\end{array}$ & $\begin{array}{l}b_{m} \\
0.131 \\
0.454 \\
\lambda_{m} \\
0.003 \\
0.855 \\
\text { HJ-Dist. } \\
0.208 \\
0.234\end{array}$ & $\begin{array}{l}b_{C Y} \\
-1.082 \\
-1.036 \\
\lambda_{C Y} \\
-0.150 \\
-0.539 \\
\text { sup-LM } \\
24.749^{* * *}\end{array}$ & $\begin{array}{l}b_{C Y \cdot m} \\
3.062 \\
0.464 \\
\lambda_{C Y \cdot m} \\
-0.007 \\
-0.551\end{array}$ \\
\hline
\end{tabular}

Note: The table reports the results of GMM estimation for the different specifications of the conditional CAPM. $D E F$ is the default spread, TERM is the term spread, $D I V$ denotes dividend yields and $T B$ is the short-term interest rate. $J A N$ is a January-Dummy which takes 1 in January and zero otherwise. $C Y$ is the cyclical component of log-industrial production. The sample period is 1969:12 - 2002:12. We report both estimates of the parameters of the SDF $\left(b_{j}\right)$ and Lambdas $\left(\lambda_{j}\right)$ calculated from these estimates. The standard errors of the $\lambda_{j} s$ are calculated using the delta method. ${ }^{*}, * *$ and ${ }^{* * *}$ means that the supLM-statistic is significant at the 10,5 or $1 \%$ level. 
We also estimate a specification of the scaled CAPM, using the lagged shortterm interest rate as a conditioning variable. Our results suggest that in contrast to the slope of the yield curve, the short term interest rate does not play a big role in explaining the variation in cross-sectional returns. None of the (scaled) factors affects the pricing kernel significantly and the estimate of the HJ-distance is approximately of the same size as the one of the unconditional CAPM. What is more, the model also suffers from parameter instability as suggested by the significant supLM-statistic by Andrews (1993).

The fourth variable considered as conditioning variable for the CAPM are aggregate dividend-yields $(D I V)$. According to the estimation results reported in Panel $\mathrm{D}$ of table 5 , both the market excess return and the interaction term between the market excess return and $D I V$ are significant components of the pricing kernel and consequently important determinants of the cross-section of returns. The model scaled by $D I V$ is superior to the standard CAPM in terms of pricing errors (smaller HJ-distance). This is also visualized by the pricing error plots in figures 2 and 4 . However, the null hypothesis of stable parameters is rejected by the supLM-Test according to Andrews (1993).

We now turn to the January-Dummy as scaling variable. According to our HJGMM estimation results provided in Panel E of table 5, the interaction between the January-Dummy and the market excess return is significant at the $10 \%$ level. This can be interpreted as evidence that the market price of risk is different in January than in other periods of the year. The January term taken by itself, however, is not a significant component of the stochastic discount factor. As revealed by the pricing error plots in 2 and 4 , the model is clearly better than the CAPM in explaining the cross-section of average returns of our size and book-to-market portfolios. Especially the pricing errors for value stocks are greatly reduced. This is a rather interesting result given the fact that the model is only a slight modification of the standard CAPM. The estimate of the HJ-Distance is the second smallest among the scaled factor models. Unfortunately, the model suffers from parameter instability, as indicated by the supLM-Test statistic which is significant at the $10 \%$ level. 
Finally, we consider a conditional version CAPM scaled by the cyclical component of industrial production. The model's empirical performance is rather unattractive. Incorporating the conditioning information into the SDF does not lead to a great reduction of pricing errors as visualized by figures 1 and 4 . None of the parameters of the SDF are significantly different from zero. Additionally, the CAPM scaled by $C Y$ suffers from parameter instability.

\subsection{Further Investigations}

In the following we report the results of additional robustness checks. We consider two further investigations to assess the empirical performance of the different model specifications. First we report the results of the evaluation of dynamic model performance according to Farnsworth et al. (2002). Then, we investigate the empirical performance of the conditional models when the Fama-French factors are added to the SDF. In particular we want to see, whether the factors of the conditional models survive in the presence of the Fama-French factors.

Dynamic Model performance The main focus of the two previous subsections has been to investigate whether the different specifications of the conditional CAPM are able to explain the cross-sectional variation of average stock returns on the German stock-market. We now turn to an analysis of how well the different models explain the time variation of the test portfolio returns. The central idea of this testing approach, which has been put forth in the paper by Farnsworth et al. (2002), is the following. Assuming that the model does a good job in capturing the time variation of the test portfolios, the model's time series pricing errors $\hat{\xi}_{t+1}=M_{t+1}(\hat{b}) R_{t+1}^{e i}$ should not be predictable using any information available as of $t$. Note that $R_{t+1}^{e i}$ in this context denotes the return of portfolio $i$ in excess of the short term interest rate. Farnsworth et al. (2002) propose to use a linear projection of the time series of pricing errors $\left\{\hat{\xi}_{t+1}\right\}$ onto the set of conditioning variables $z_{t}$. The standard deviation of the fitted values of this regression then serves as an indicator of how well the model captures the time variation of the 
respective portfolio return.

We conduct this exercise for our 16 test portfolios. Table 6 reports the average of the standard deviations of the fitted values across the test portfolios. In addition, the minimum and maximum standard deviation are provided. A low average standard deviation indicates that the specific model is good at capturing timeseries predictability of the excess returns of test portfolios.

Table 6: Dynamic Model performance

\begin{tabular}{lccc}
\hline & Mean & Minimum & Maximum \\
\hline Panel A: Unconditional Models & & & \\
CAPM & 0.805 & 0.580 & 1.205 \\
Fama-French & 0.810 & 0.586 & 1.193 \\
& & & \\
Panel B: Conditional Models & & & \\
CAPM scaled by DEF & 1.070 & 0.643 & 1.630 \\
CAPM scaled by TERM & 1.591 & 1.014 & 1.877 \\
CAPM scaled by TB & 1.071 & 0.775 & 1.422 \\
CAPM scaled by DIV & 1.068 & 0.671 & 1.681 \\
CAPM scaled by JAN & 0.839 & 0.486 & 1.184 \\
CAPM scaled by CY & 0.895 & 0.643 & 1.334 \\
\hline \hline
\end{tabular}

Note: The table reports the results of the test for dynamic model performance proposed by Farnsworth et al. (2002). The procedure is based on a regression of the models' time series pricing errors for the 16 portfolios on the set of conditioning variables $z_{t}=$ $\left(D E F_{t}, T E R M_{t}, T B_{t}, D I V_{t}, C Y_{t}\right)^{\prime}$. The table reports the mean of the standard deviations of the regressions' fitted values across the 16 portfolios. Moreover the minimum and the maximum standard deviation across the 16 test portfolios are reported. A low standard deviation indicates that the particular model specification performs well in capturing the time-series predictability of the test asset excess returns. Panel A provides results for the unconditional factor models whereas panel B gives the results of the different versions of the conditional CAPM. The sample period is 1969:12 - 2002:12.

The table shows that unconditional models apparently perform pretty well in capturing the time-series predicability of the portfolio excess returns. The unconditional CAPM has the lowest average standard deviation of all investigated models. We do not find that conditional models tend to outperform unconditional ones in this test. It is striking that the different specifications of the conditional CAPM, especially those with a good cross-sectional performance, have a clearly worse performance with regard to time series predictability relative to unconditional specifications such as the unconditional CAPM and the Fama-French model. An 
exception is the CAPM scaled by $J A N$ which has both low cross-sectional pricing errors and does a relatively good job in terms of dynamic model performance. Our findings are similar to those reported by Farnsworth et al. (2002). The authors find that conditional versions of the CAPM and the Fama-French model perform worse than their unconditional counterparts, whereas other conditional models they consider in their paper tend to do better than unconditional specifications.

Factor Combinations An additional robustness check for the conditional specifications of the CAPM is to see whether the factors are sufficient for pricing the cross-section of returns or whether they are driven out once other factors are included in the specification of the pricing kernel. For this purpose, we add the Fama-French factors $S M B$ and $H M L$ to the SDF

$$
M_{t+1}=b_{0,1}+b_{0,2} z_{t}+b_{1,1}^{\prime} f_{t+1}+b_{1,2}^{\prime}\left(f_{t+1} z_{t}\right)+c_{1} S M B_{t+1}+c_{2} H M L_{t+1} .
$$

To assess whether the Fama-French factors provide explanatory power in addition to the original set of factors we use a likelihood-ratio test. ${ }^{14}$ We first estimate the unrestricted model in (10). Then we rerun the estimation imposing $c_{1}=c_{2}=0$ as implied by the respective specification of the conditional CAPM. The teststatistic based on the difference between the $J_{T}$-statistics of the restricted and the unrestricted model is asymptotically distributed $\chi^{2}$ with two degrees of freedom. Table 7 contains the results of the likelihood-ratio tests. Adding the Fama-French factors can influence the results considerably for some conditioning variables. As shown in table 7 , the test statistic is significant in the case of the CAPM scaled by $D E F$ and TB (10\% level) and in particular for the CAPM scaled by $C Y$ ( $1 \%$ level). The model scaled by the term spread TERM and the CAPM scaled by the January Dummy $J A N$ remain largely unaffected by the inclusion of the Fama-French factors, which provides further evidence on their good empirical performance.

\footnotetext{
${ }^{14}$ This test is described for instance in Cochrane (2001, p.258).
} 
Table 7: Combining Factors: Likelihood-ratio Tests

\begin{tabular}{llc}
\hline Model & $\chi_{(2)}^{2}$ & $p$-value \\
\hline CAPM scaled by DEF & 5.191 & 0.075 \\
CAPM scaled by TERM & 1.176 & 0.555 \\
CAPM scaled by TB & 5.839 & 0.054 \\
CAPM scaled by DIV & 3.348 & 0.188 \\
CAPM scaled by $J A N$ & 0.540 & 0.763 \\
CAPM scaled by $C Y$ & 12.347 & 0.002 \\
\hline \hline
\end{tabular}

Note: The table reports the results of the $\chi^{2}$-difference test in order to assess the additional explanatory power of the Fama-French factors. First, we estimate an unrestricted model including the factors of the conditional CAPM plus the Fama-French factors $S M B$ and $H M L$ using two-stage GMM. Second, we estimate a restricted model which only includes the factors of the conditional CAPM. The test statistic based on the difference of the $J_{T}$-statistics of the restricted and unrestricted models is distributed $\chi_{(2)}^{2}$. The sample period is 1969:12 - 2002:12.

\section{Conclusion}

This paper investigated whether conditional versions of the CAPM, allowing for time-variation of the parameters in the stochastic discount factor, are able to explain the cross-section of German stock returns better than unconditional factor models such as the conventional CAPM or the three-factor model by Fama and French (1993). Previous research suggests that scaling the factors with conditioning variables improves the empirical performance of unconditional asset pricing models. Since prior research focused primarily on the U.S. stock market, the aim of this paper was to investigate whether this also holds empirically for the German stock market.

Using a cross-section of 16 portfolios sorted by size and book-to-market, our findings suggest that, the empirical performance of the CAPM can be enhanced considerably by allowing the parameters of the stochastic discount factor to vary over time through the incorporation of conditioning information. We focus on several variables, which (according to previous research) are associated with market expectations on future market excess returns or business cycle conditions. The selection of the term spread, default spread, short-term interest rate and aggregate dividend yields as conditioning variables largely followed Ferson and Harvey (1999). 
In addition, we also considered a January-Dummy and the cyclical component of industrial production as proposed by Hodrick and Zhang (2001).

The different conditioning variables do not all lead to the same degree of improvement. In particular, we find that the CAPM scaled by the term spread TERM has a large explanatory power for the German cross-section of stock returns with pricing errors smaller than those of the Fama-French three-factor model. Furthermore, the model has the lowest HJ-distance of all models evaluated in this study. Additional robustness checks demonstrate that the model is robust to an inclusion of the Fama-French factors into the SDF. However, the model's performance in capturing the time-series predictability of the test asset returns is quite unsatisfactory. Moreover, we find that a simple extension of the CAPM allowing for time-variation of the parameters of the SDF in January and non-January months does a clearly better job than the static CAPM in capturing the "value premium". We also used the test procedure suggested by Andrews (1993), in order to assess whether structural shifts in the parameters may affect the asset pricing model specification. Our estimations show that parameter instability is present when the CAPM is scaled by the short-term interest rate $T B$, dividend yields $D I V$, the January dummy $J A N$ and the cyclical component of industrial production $C Y$. However, we do not find parameter instability to be important for the CAPM scaled by the term spread TERM or the default spread DEF. Moreover, we find evidence for structural breaks in the case of the Fama-French model which calls for caution when using the model in corporate finance applications on the German stock market.

In the light of the evidence for structural shifts in the parameters of the FamaFrench model, it would be interesting in further research to analyze potential economic reasons. Given the prominence of the Fama-French model in academic research (not only in empirical asset pricing but also corporate finance applications), taking a closer look at the stability of the Fama-French model over time may prove beneficial. Furthermore, more research is needed on what macroeconomic risks the Fama-French factors $S M B$ and $H M L$ are proxies for. The debate 
is still not fully resolved yet as mentioned above. We suppose that further evidence from non U.S. markets may shed further light on this issue.

In this paper, we investigate parsimonious model specifications where different conditioning variables are analyzed separately. Stability issues are addressed using the test by Andrews (1993). It may also be useful to consider optimal combinations of conditioning variables. Wang (2004) has proposed a procedure for optimally choosing combinations of instruments. He shows that by doing so, the out-of sample performance of conditional asset pricing models can be enhanced substantially. Selecting conditioning variables optimally as in Wang (2004) may prove beneficial in obtaining model specifications which performs well both in pricing the crosssection and are stable over time. 


\section{References}

Ahn, S. C. and Gadarowski, C.: 2004, Small sample properties of the GMM specification test based on the Hansen-Jagannathan distance, Journal of Empirical Finance 11, 109-132.

Andrews, D.: 1993, Tests for parameter instability and structural change with unknown change point, Econometrica 61, 821-856.

Ang, A. and Bekaert, G.: 2005, Stock return predictability: Is it there? Working paper, Columbia University.

Ang, A. and Chen, J.: 2005, CAPM over the long run: 1926-2001. Working paper, Columbia University.

Banz, R. W.: 1981, The relationship between return and market value of common stocks, Journal of Financial Economics 9, 3-18.

Basu, S.: 1983, The relationship between earnings yield, market value and return for NYSE common stock: further evidence, Journal of Financial Economics 12, 129-156.

Beiker, H.: 1993, Überrenditen und Risiken kleiner Aktiengesellschaften. Eine theoretische und empirische Analyse des deutschen Kapitalmarktes von 1966 bis 1989., Müller Botermann, Aachen.

Bunke, O., Sommerfeld, V. and Stehle, R.: 1999, Semiparametric modelling of the cross-section of expected returns in the German stock market. Humboldt Universität Berlin.

Campbell, J. Y. and Shiller, R. J.: 1988, The dividend-price ratio and expectations of future dividends and discount factors, Review of Financial Studies $\mathbf{1}(3), 195-228$.

Cochrane, J. H.: 1996, A cross-sectional test of an investment-based asset pricing model, Journal of Political Economy 104(3), 572-621. 
Cochrane, J. H.: 2001, Asset Pricing, Princeton University Press, NJ.

Daniel, K. and Titman, S.: 1997, Evidence on the characteristics of cross sectional variation in stock returns, Journal of Finance 52, 1-33.

Fama, E. F. and French, K. R.: 1989, Business conditions and expected returns on stocks and bonds, Journal of Financial Economics 25(1), 23-49.

Fama, E. F. and French, K. R.: 1992, The cross-section of expected stock returns, Journal of Finance 47(2), 427-465.

Fama, E. F. and French, K. R.: 1993, Common risk factors in the returns on stocks and bonds, Journal of Financial Economics 33, 3-56.

Fama, E. F. and French, K. R.: 1995, Size and book-to-market factors in earnings and returns, Journal of Finance 50, 131-156.

Fama, E. F. and French, K. R.: 1996, Multifactor explanations of asset pricing anomalies, Journal of Finance 51(1), 55-84.

Fama, E. F. and MacBeth, J.: 1973, Risk, return and equilibrium: Empirical tests, Journal of Political Economy 81, 607-636.

Farnsworth, H., Ferson, W., Jackson, D. and Todd, S.: 2002, Performance evaluation with stochastic discount factors, Journal of Business 75, 473-503.

Ferson, W. E. and Harvey, C. R.: 1991, The variation of economic risk premiums, Journal of Political Economy 99, 385-415.

Ferson, W. E. and Harvey, C. R.: 1999, Conditioning variables and the cross section of stock returns, Journal of Finance 54(4), 1325-1360.

Gehrke, N.: 1994, Tobin's q - Die Beziehung zwischen Buch- und Marktwerten deutscher Aktiengesellschaften, Gabler Edition Wissenschaft, Wiesbaden.

Ghysels, E.: 1998, On stable factor structures in the pricing of risk: Do timevarying betas help or hurt?, Journal of Finance 53, 549-573. 
Goyal, A. and Welch, I.: 2004, A comprehensive look at the empirical performance of equity premium prediction. Working paper, NBER.

Hafner, C. M. and Herwartz, H.: 1999, Time-varying market price of risk in the CAPM approaches, empirical evidence and implications. Working paper, HU Berlin.

Hansen, L. P.: 1982, Large sample properties of generalized method of moments estimators, Econometrica 50(4), 1029-1054.

Hansen, L. P. and Jagannathan, R.: 1997, Assessing specification errors in stochastic discount factor models, Journal of Finance 52(2), 557-590.

Harvey, C. R.: 1989, Time-varying conditional covariances in tests of asset pricing models, Journal of Financial Economics 24, 289-318.

Hodrick, R. J. and Prescott, E.: 1997, Postwar U.S. business cycles: an empirical investigation, Journal of Money, Credit and Banking 29, 1-16.

Hodrick, R. J. and Zhang, X.: 2001, Evaluating the specification errors of asset pricing models, Journal of Financial Economics 62, 327-376.

Jagannathan, R. and Wang, Z.: 1996, The conditional CAPM and the cross-section of expected returns, Journal of Finance 51(1), 3-53.

Lettau, M. and Ludvigson, S.: 2001a, Consumption, aggregate wealth, and expected stock returns, Journal of Finance 56(3), 815-849.

Lettau, M. and Ludvigson, S.: 2001b, Ressurrecting the (C)CAPM: A crosssectional test when risk premia are time-varying, Journal of Political Economy 109, 1238-1287.

Lewellen, J. and Nagel, S.: 2005, The conditional CAPM does not explain assetpricing anomalies. forthcoming Journal of Financial Economics.

Li, Q., Vassalou, M. and Xing, Y.: 2001, An investment-growth asset pricing model. CEPR working paper. 
Liew, J. and Vassalou, M.: 2000, Can book-to-market, size and momentum be risk factors that predict economic growth?, Journal of Financial Economics 57, 221-245.

Merton, R. C.: 1973, An intertemporal capital asset pricing model, Econometrica 41(5), 867-887.

Petkova, R.: 2006, Do the Fama-French factors proxy for innovations in predictive variables?, Journal of Finance 61, 581-612.

Rosenberg, B., Reid, K. and Lanstein, R.: 1985, Persuasive evidence on market inefficiency, Journal of Portfolio Management 11, 9-17.

Ross, S. A.: 1976, The arbitrage theory of capital asset pricing, Journal of Economic Theory 13, 341-360.

Sattler, R. R.: 1994, Renditeanomalien am deutschen Aktienmarkt, Aachen.

Scheicher, M.: 2000, Time-varying risk in the German stock market, The European Journal of Finance 6, 70-91.

Schulz, A. and Stehle, R.: 2002, Buchwert-Marktwert-Verhältnis, Size und Beta als Erklärungsvariable für die Renditen deutscher Aktien. Humboldt Universität Berlin.

Shanken, J.: 1992, On the estimation of beta pricing models, Review of Financial Studies 5, 1-34.

Stehle, R.: 1997, Der Size-effekt am deutschen Aktienmarkt, Zeitschrift für Bankrecht und Bankwirtschaft 9, 237-260.

Stock, D.: 2002, Zur Relevanz von Marktmodell-Anomalien für den deutschen Aktienmarkt, Frankfurt am Main.

Wallmeier, M.: 2000, Determinanten erwarteter Renditen am deutschen Aktienmarkt - Eine empirische Untersuchung anhand ausgewählter Kennzahlen, Zeitschrift für betriebswirtschaftliche Forschung 52, 27-57. 
Wang, K. Q.: 2004, Conditioning information, out-of-sample validation, and the cross-section of stock returns. Working paper, University of Toronto.

Ziegler, A., Schröder, M., Schulz, A. and Stehle, R.: 2005, Multifaktormodelle zur Erklärung deutscher Aktienrenditen: Eine empirische Analyse. forthcoming Zeitschrift für Betriebswirtschaftliche Forschung (ZfbF). 


\section{A The Fama-MacBeth Procedure}

Beside HJ-GMM we also report results from the two-step cross-sectional regression by Fama and MacBeth (1973) (FMB) which has a long tradition in empirical asset pricing. First, a time series regression is carried out by regressing excess returns $R_{i, t}$ on the factors for all assets $i$.

$$
R_{i, t}=a_{i}+\beta_{i}^{\prime} f_{t}+\epsilon_{i, t} ; \quad i=1, \ldots, N, \quad t=1, \ldots, T
$$

The next step is to use the estimated $\widehat{\beta}_{i}$ as explanatory variables in the crosssectional regression in order to estimate the factor risk premia $\lambda_{j}$. Instead of estimating one cross-sectional regression of average portfolio returns on the betas, the following regression is estimated at every point of time $t=1, \ldots, T$.

$$
R_{i ; t}=\widehat{\beta}_{i}^{\prime} \lambda_{t}+\xi_{i, t}
$$

The estimated factor risk premia are calculated as the time series averages of the estimates of each point in time:

$$
\widehat{\lambda}=\frac{1}{T} \sum_{t=1}^{T} \widehat{\lambda}_{t}
$$

Fama and MacBeth (1973) suggest to interpret $\left\{\widehat{\lambda}_{t}\right\}$ as a random sample. Standard errors of $\lambda_{j}$ are then calculated based on the time series of the estimated $\hat{\lambda}_{t}$ :

$$
\text { s.e. }(\widehat{\lambda})=\frac{1}{\sqrt{T}}\left[\frac{1}{T} \sum_{t=1}^{T}\left(\widehat{\lambda}_{t}-\widehat{\lambda}\right)^{2}\right]^{1 / 2} \text {. }
$$

A well known problem of the FMB approach is the errors-in-variables problem since only estimated betas enter the cross-sectional regression and not the true betas. Shanken (1992) has derived a correction term to alleviate this problem. We report the Shanken-adjusted along with conventional $t$-statistics. Furthermore, we report the cross-sectional $R^{2}$ as an intuitive measure of model fit. 


\section{B Additional Figures and Tables}

Table 8: FMB estimation: CAPM and Fama-French Model.

\begin{tabular}{lcccc}
\hline Panel A: CAPM & & & \\
\hline Factor risk price: & $\lambda_{m}$ & & $R^{2}$ (adj.) \\
Estimate & 0.002 & & & 0.174 \\
$t$-statistic & 0.748 & & & \\
$t$-statistic (adj.) & 0.748 & & & \\
\hline Panel A: Fama-French Model & & \\
\hline Factor risk price: & $\lambda_{m}$ & $\lambda_{S M B}$ & $\lambda_{H M L}$ & $R^{2}$ (adj.) \\
Estimate & 0.002 & -0.003 & 0.003 & 0.478 \\
$t$-statistic & 0.806 & -1.853 & 2.258 & \\
$t$-statistic (adj.) & 0.795 & -1.827 & 2.227 & \\
\hline \hline
\end{tabular}

Note: The table reports the results of Fama-Macbeth cross-sectional regressions for the unconditional CAPM and Fama-French model. The sample period is 1969:12 - 2002:12. Both conventional $t$-Statistics and Shanken-adjusted $t$-Statistics are reported. 
Table 9: FMB estimation: scaled CAPM.

\begin{tabular}{|c|c|c|c|c|}
\hline \multicolumn{5}{|c|}{ Panel A: CAPM scaled by DEF } \\
\hline $\operatorname{Lambda}\left(\lambda_{j}\right):$ & $\lambda_{m}$ & $\lambda_{D E F}$ & $\lambda \lambda_{D E F \cdot m}$ & $R^{2}$ (adj.) \\
\hline Estimate & 0.003 & 0.567 & 0.015 & 0.320 \\
\hline$t$-statistic & 1.042 & 1.641 & 1.094 & \\
\hline$t$-statistic (adj.) & 0.876 & 1.380 & 0.920 & \\
\hline \multicolumn{5}{|c|}{ Panel B: CAPM scaled by TERM } \\
\hline $\operatorname{Lambda}\left(\lambda_{j}\right):$ & $\lambda_{m}$ & $\lambda_{T E R M}$ & $\lambda_{T E R M \cdot m}$ & $R^{2}$ (adj.) \\
\hline Estimate & 0.003 & -0.851 & -0.029 & 0.571 \\
\hline$t$-statistic & 0.939 & -2.572 & -2.289 & \\
\hline$t$-statistic (adj.) & 0.674 & -1.846 & -1.643 & \\
\hline \multicolumn{5}{|c|}{ Panel C: CAPM scaled by TB } \\
\hline $\operatorname{Lambda}\left(\lambda_{j}\right):$ & $\lambda_{m}$ & $\lambda_{T B}$ & $\lambda_{T B \cdot m}$ & $R^{2}$ (adj.) \\
\hline Estimate & 0.002 & 0.336 & 0.003 & 0.217 \\
\hline$t$-statistic & 0.749 & 0.913 & 0.392 & \\
\hline$t$-statistic (adj.) & 0.706 & 0.860 & 0.369 & \\
\hline \multicolumn{5}{|c|}{ Panel D: CAPM scaled by DIV } \\
\hline $\operatorname{Lambda}\left(\lambda_{j}\right):$ & $\lambda_{m}$ & $\lambda_{D I V}$ & $\lambda_{D I V \cdot m}$ & $R^{2}$ (adj.) \\
\hline Estimate & -0.001 & -0.704 & 0.013 & 0.419 \\
\hline$t$-statistic & -0.304 & -1.972 & 2.023 & \\
\hline$t$-statistic (adj.) & -0.241 & -1.564 & 1.604 & \\
\hline \multicolumn{5}{|c|}{ Panel E: CAPM scaled by JAN } \\
\hline $\operatorname{Lambda}\left(\lambda_{j}\right):$ & $\lambda_{m}$ & $\lambda_{J A N}$ & $\lambda_{J A N \cdot m}$ & $R^{2}$ (adj.) \\
\hline Estimate & 0.002 & 0.021 & 0.012 & 0.486 \\
\hline$t$-statistic & 0.818 & 0.343 & 3.245 & \\
\hline$t$-statistic (adj.) & 0.609 & 0.255 & 2.415 & \\
\hline \multicolumn{5}{|c|}{ Panel F: CAPM scaled by CY } \\
\hline $\operatorname{Lambda}\left(\lambda_{j}\right):$ & $\lambda_{m}$ & $\lambda_{C Y}$ & $\lambda_{C Y \cdot m}$ & $R^{2}$ (adj.) \\
\hline Estimate & 0.002 & -0.334 & -0.016 & 0.236 \\
\hline$t$-statistic & 0.744 & -1.039 & -1.168 & \\
\hline$t$-statistic (adj.) & 0.676 & -0.944 & -1.062 & \\
\hline
\end{tabular}

Note: The table reports the results of Fama-Macbeth cross-sectional regressions for different specifications of the scaled CAPM. $D E F$ is the default spread, TERM is the term spread, $D I V$ denotes dividend yields and $T B$ is the short-term interest rate. $J A N$ is a January-Dummy which takes 1 in January and zero otherwise. $C Y$ denotes the cyclical component of (log)industrial production. The sample period is 1969:12 - 2002:12. Both conventional $t$-Statistics and Shanken-adjusted $t$-Statistics are reported. 
Figure 3: FMB cross-sectional regression: CAPM and Fama-French Model, Fitted versus Actual Mean Excess Returns, in \% per month, 16 Fama-French portfolios.
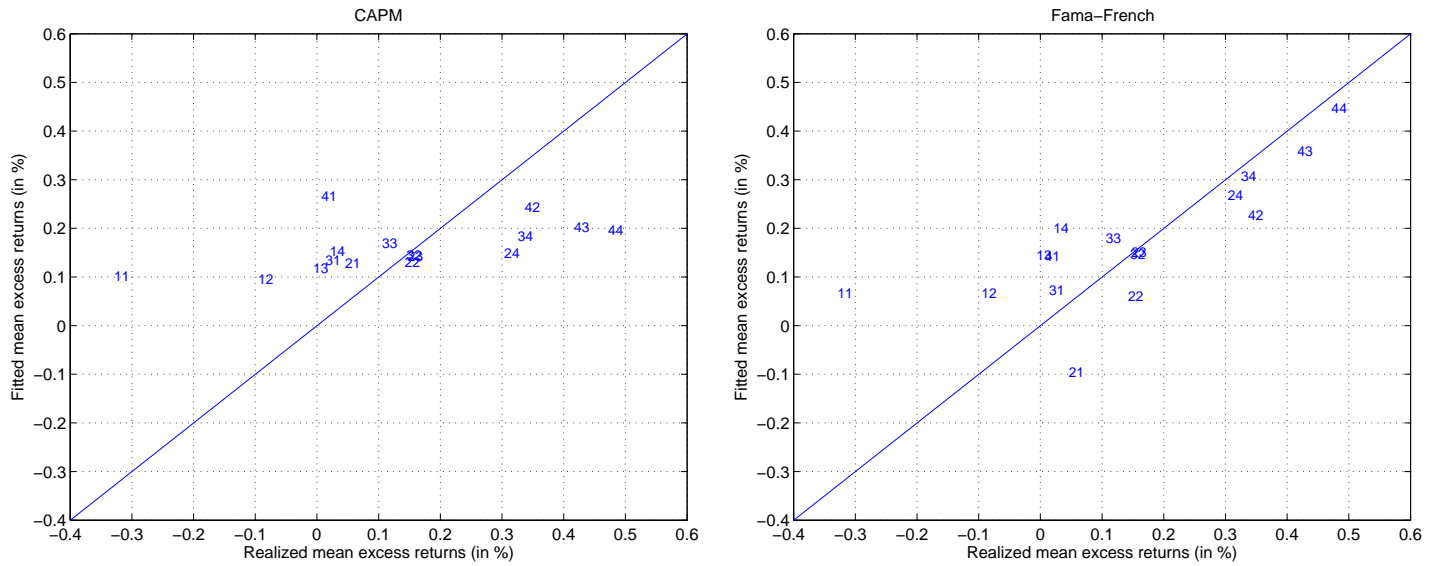

Note: The graphs were generated using the results from the Fama-Macbeth estimation. Mean realized excess returns (horizontal axis) are plotted against the mean realized excess returns implied by the respective asset pricing model (vertical axis). The first digit refers to the size quartile ( $1=$ Small, $4=\mathrm{Big})$ and the second digit refers to the book-to-market quartile $(1=$ Low, $4=$ High). The test asset are 16 excess returns of size and book-to-market portfolios as well as the gross return of our proxy for the risk-free asset. The sample period is 1969:12 - 2002:12. The two graphs show results for the CAPM and the Fama-French-Model. 
Figure 4: FMB cross-sectional regression: Scaled CAPM, Fitted versus Actual Mean

Excess Returns, in \% per month, 16 Fama-French portfolios.
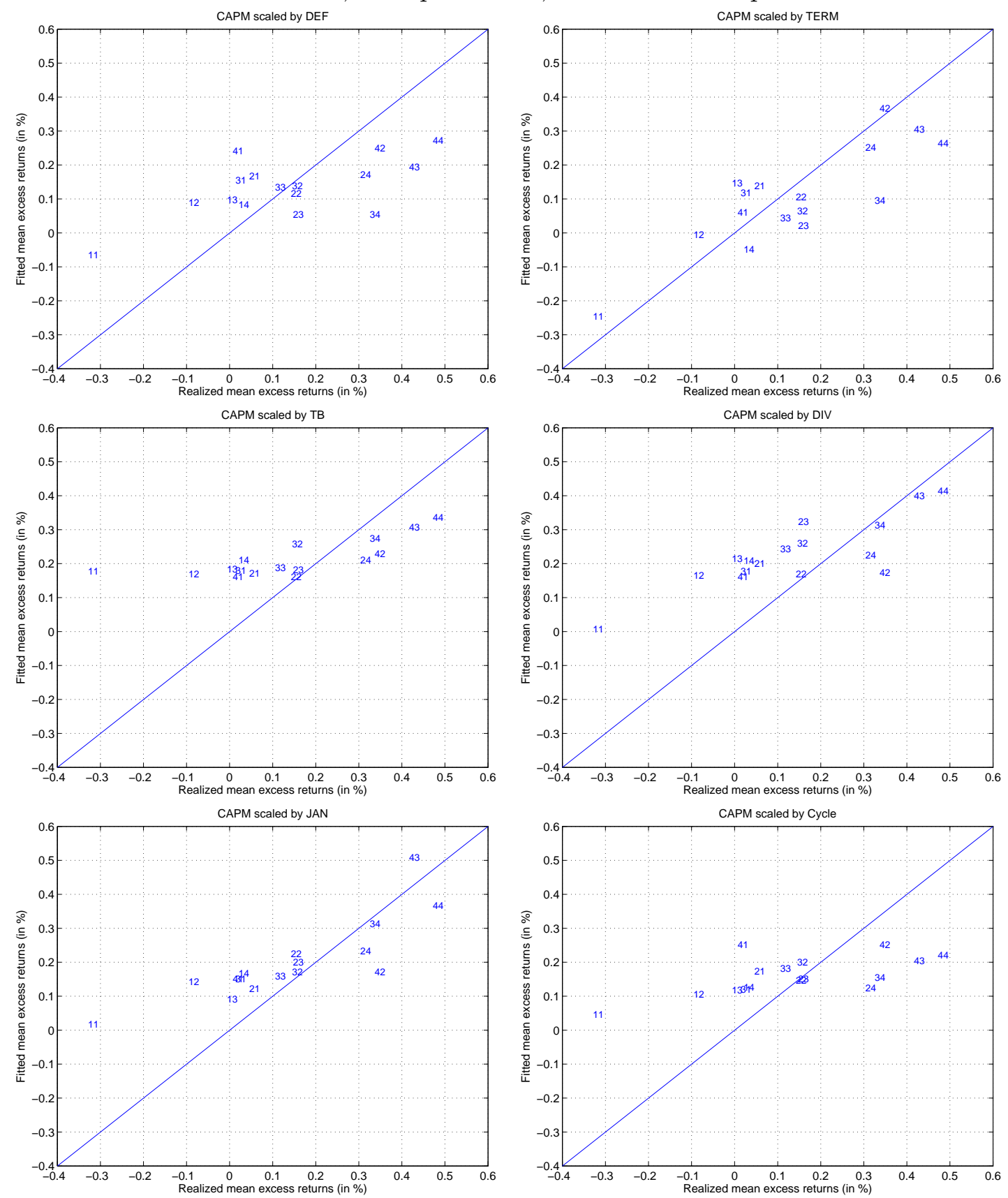

Note: The graphs were generated using the results from the Fama-Macbeth estimation. Mean realized excess returns (horizontal axis) are plotted against the mean realized excess returns implied by the respective asset pricing model (vertical axis). The first digit refers to the size quartile (1=Small, $4=\mathrm{Big})$ and the second digit refers to the book-to-market quartile $(1=\mathrm{Low}$, $4=$ High). The test asset are 16 excess returns of size and book-to-market portfolios as well as the gross return of our proxy for the risk-free asset. The sample period is 1969:12 - 2002:12. The upper two graphs show results for the CAPM scaled by the default spread $D E F$ and the term spread TERM. In the middle the pricing error plots of the CAPM scaled by the short-term interest rate $T B$ and by dividend yields $D I V$ are illustrated. At the bottom plots for the CAPM scaled by the January dummy $J A N$ and the cyclical component of industrial production $C Y$ are presented. 